\title{
Interactions Among a Soil Organic Amendment, Nematodes, and the Nematode-Trapping Fungus Dactylellina candidum
}

\author{
B. A. Jaffee
}

Department of Nematology, University of California, Davis 95616-8668.

Accepted for publication 10 July 2006.

ABSTRACT

\begin{abstract}
Jaffee, B. A. 2006. Interactions among a soil organic amendment, nematodes, and the nematode-trapping fungus Dactylellina candidum. Phytopathology 96:1388-1396.

When alfalfa leaves (Medicago sativa) are added to soil, both the nematode-trapping fungus Dactylellina candidum and microbivorous nematodes increase. To determine whether the response of the fungus to alfalfa depends on consumption of bacterivorous and fungivorous nematodes, soil microcosm experiments were performed. D. candidum did not increase if alfalfa leaves were added to soil lacking nematodes, but did increase if nematodes were added to soil lacking alfalfa leaves. Although these results indicate that the response of $D$. candidum to alfalfa depends
\end{abstract}

on nematodes, $D$. candidum and microbivorous nematodes did not exhibit classical predator-prey dynamics (i.e., $D$. candidum seldom reduced numbers of resident nematodes and, after initially increasing in alfalfaamended soil, numbers of $D$. candidum then decreased, whereas numbers of nematodes continued to increase). Fungivorous nematodes were abundant in alfalfa-amended soil, and their potential to suppress trapping fungi requires more research

Additional keywords: Arthrobotrys oligospora, bacterivorous nematodes, Hirsutella rhossiliensis, litter mass loss, organic amendments, saprophytic competition.

Studied sporadically for nearly 80 years, nematode-trapping fungi remain poorly understood. We know that at least a few species occur in nearly every soil (1), that some species seem more dependent on nematodes than others $(25,26)$, and that attempts to use them to control plant-parasitic nematodes have usually failed $(8,36)$. We also know that their numbers increase with addition of crop residues to soil $(8,39)$ and that they suppress animal-parasitic nematodes in feces $(31,32,38,40)$. What we don't know is why dead organic matter, in the form of crop residue or animal feces, often seems central to their biology.

To explain how organic matter affects trapping fungi, researchers have proposed two mechanisms. The first assumes that the more parasitic or predacious species of trapping fungi obtain all or most of their carbon, energy, and nitrogen from the microbivorous nematodes that increase whenever organic matter is added to soil (34). The second proposed mechanism assumes that the more saprophytic species of trapping fungi directly use dead organic matter as a source of carbon and energy and use nematodes as a source of supplemental nitrogen $(2,37)$.

Although both mechanisms are reasonable and complementary, determining which substrates fungi use in soil is difficult, and quantitative supporting data are incomplete and unconvincing. Maurice Linford and colleagues proposed the first mechanism in the 1930s, and they clearly believed that trapping fungi used living nematodes, not dead organic matter, as carbon and energy sources (34). But, they provided almost no quantitative data on the numbers or activity of the fungi in soil. In the 1960s, Cooke (8) proposed the second mechanism after adding organic matter to soil and finding that changes in trap number (largely adhesive networks) seemed unrelated to changes in nematode number. Because trap number should be related to nematode number if the fungi depend primarily on nematodes for carbon and energy,

Corresponding author: B. Jaffee; E-mail address: bajaffee@ ucdavis.edu

DOI: 10.1094/PHYTO-96-1388

() 2006 The American Phytopathological Society
Cooke inferred that the changes in trap number were largely based on saprophytism. Other support for the second mechanism was provided by Jansson and Nordbring-Hertz $(25,26)$, who divided trapping fungi into parasitic and saprophytic groups based on spontaneous versus induced trap formation on agar (the more parasitic species produce traps spontaneously but the more saprophytic species must be induced by addition of nematodes), growth rate on agar (parasitic species grow more slowly), attractiveness to nematodes on agar (parasitic species are more attractive), trap type (for example, those forming adhesive knobs seem more parasitic than those forming adhesive networks), and other characteristics. The second mechanism also was supported by data showing that many trapping fungi produce cellulase, which would be useful in degrading plant residues but not nematodes (2).

In spite of this evidence, the second mechanism remains unmatter in nonsterile soil. With respect to the first mechanism, certain fungi that form adhesive knobs or constricting rings increase when nematodes are added to soil without organic amendment, suggesting that these fungi respond directly to nematodes alone (22). Some "endoparasitic fungi," which use adhesive spores rather than traps to attack nematodes, also respond directly to nematodes alone (21) and one experiment, in particular, strongly supported the first mechanism as proposed by Linford et al. (34): in initially sterile microcosms that subsequently were infested with microorganisms and nematodes, the endoparasitic fungus Drechmeria coniospora did not respond to organic amendments unless nematodes were present (3). Similar data with a putatively parasitic species of trapping fungus have not been published.

A trapping fungus that might behave like an endoparasite, that might depend much more on parasitism than on saprophytism, is Dactylellina candidum (Nees: Fr.) Y. Li (= Dactylellina haptotyla (Drechsler) M. Scholler) (33). D. candidum produces stalked, adhesive knobs and is useful as a study organism because it can be quantified by both bioassay and dilution plating. $D$. candidum certain because no data demonstrate direct use of dead organic 
parasitism of nematodes in soil (as determined by bioassay) and D. candidum propagule density (as determined by soil dilution plating) were positively correlated $(18,19)$.

D. candidum also may have use as a control agent against plantparasitic nematodes. When formulated as assimilative hyphae in alginate pellets and added to field soil, D. candidum was much less sensitive to biotic inhibition than was the endoparasitic fungus Hirsutella rhossiliensis (17), and D. candidum propagule density and parasitism of assay nematodes increased when soil was amended with organic matter (19). Linford and colleagues would have predicted that this increase was based on parasitism of bacterivorous and fungivorous nematodes rather than on saprophytism. To test that prediction, the current study measured the response of $D$. candidum to alfalfa amendments in the presence and absence of nematodes and with different levels of microbial competition. The current study also determined whether D. candidum suppressed resident nematode numbers, whether changes in $D$. candidum propagule density were correlated with changes in resident nematode numbers, and whether $D$. candidum responded to nematode additions in the absence of organic amendments.

\section{MATERIALS AND METHODS}

Soil treatments. Soil was collected adjacent to vines, 5 to $20 \mathrm{~cm}$ deep, from a commercial vineyard near Lodi CA, referred to as "site 4" in other studies (19). This loamy sand $\left(\mathrm{pH}_{\text {water }}=7.0\right)$ was used because it contained little organic matter $(<1 \%)$ and only small numbers of nematodes and nematode-trapping fungi (19). Moreover, the soil supported substantial numbers and activity of $D$. candidum when the fungus was added to it (17-19), but the fungus has not been detected as a resident in this soil. The soil was passed through a $2-\mathrm{mm}$ sieve and stored at $10^{\circ} \mathrm{C}$ for $<20$ days before use, except that soil was stored for 37 days in trial 2 of experiment 4 . Water release data for this soil have been published (16).

To heat soil as described in the experiments, the soil water content was adjusted to between 8 and $9 \%$ ( 8 to $9 \mathrm{~g}$ of water per $100 \mathrm{~g}$ of dry soil) on day -3 ; soil moisture was made moderate and uniform among experiments to increase the efficacy and reproducibility of the heat treatments. On day $-2,1,670 \mathrm{~g}$ of soil (dry weight equivalent) was placed in each of two 20-by-20-by-5$\mathrm{cm}$ glass pans to a depth of $3.7 \mathrm{~cm}$; one temperature recorder (Hobo-Temp model; Onset Computer Corporation, Pocasset, MA), reading temperature at 10 -min intervals, was placed in the center of the soil mass in each pan. The pans were covered with aluminum foil and placed in a preheated oven (see experiments for temperatures). After $5.0 \mathrm{~h}$, the oven was turned off and the door was opened. When cool, the pans were removed from the oven and the soil was transferred to a plastic bag, which was left unsealed on the laboratory bench for $14 \mathrm{~h}$. On day -1 , the soil was mixed, sampled to determine soil water content, and returned to $10^{\circ} \mathrm{C}$. On day 0 , water content was adjusted to $10.0 \%(\approx-10 \mathrm{kPa})$, and soil was added to vials as described below.

Effect of heat treatment on nematodes and litter mass loss (experiment 1). Experiment 1 attempted to identify a heat treatment of soil that eliminated nematodes but did not reduce saprophytic competition for an organic amendment (alfalfa leaves, Medicago sativa). If such a treatment could be identified, subsequent experiments could then compare the response of $D$. candidum to alfalfa in the presence and absence of nematodes but in the presence of a competitive microbial community. In experiment 1 , the level of saprophytic competition remaining after heat treatment was inferred from changes in mass loss of alfalfa leaves; if mass loss in heat-treated soil was less than mass loss in nonheated soil, I assumed that saprophytic competition was reduced, and if mass loss was similar in heated and nonheated soil, I assumed that saprophytic competition remained substantial.
As described above, soil was not heated or was placed for $5 \mathrm{~h}$ in an oven at $40,45,50,55$, or $60^{\circ} \mathrm{C}$. On day 0 , the soil was packed into $25-\mathrm{ml}$ plastic vials. The bottom of each vial had five holes (6 $\mathrm{mm}$ in diameter) and, therefore, was 36\% "open" to permit gas exchange. The soil column was $17 \mathrm{~mm}$ high and $\approx 25 \mathrm{~mm}$ in diameter; each vial contained $24 \mathrm{~g}$ of soil (dry weight equivalent) at $1.4 \mathrm{~g}$ of soil $/ \mathrm{cm}^{3}$. To prevent the soil from falling through the holes, the inner bottom of the vial was covered with a disc of polyester mesh.

Just before the soil was added to each vial, $\approx 10$ air-dried and preweighed alfalfa leaflets $(9.7 \%$ water content), which had not been treated with pesticides and which had been selected for uniformity from vigorously growing shoot tips, were gently mixed into the soil. Each leaflet was $\approx 22 \mathrm{~mm}$ long and $9 \mathrm{~mm}$ at its widest, with $155 \mathrm{~mm}^{2}$ of surface area. The alfalfa contained $44.9 \%$ carbon and $5.8 \%$ nitrogen, giving a $\mathrm{C}: \mathrm{N}$ ratio of $8: 1$. The mass of leaflets added to each vial was recorded, and this value ranged from 70 to $80 \mathrm{mg}$. The vials were sealed with a plastic lid containing a 1-mm hole and were placed on a raised metal screen in covered plastic boxes so that the bottom of each vial was $3 \mathrm{~cm}$ above the bottom of the box (to increase gas exchange). Moist tissues were placed on the bottom of the box to maintain humidity. The boxes were sealed in plastic bags and then placed in a $20^{\circ} \mathrm{C}$ incubator. To prevent organisms from moving between vials with different heat treatments, a different box was used for each temperature treatment. To reduce the effect of box position in the incubator, boxes were repositioned randomly within the incubator twice during the experiment.

After 28 days, the contents of each vial were placed in a 1-liter beaker. Water was added, and the soil suspension was stirred gently with a spatula and then allowed to settle for $10 \mathrm{~s}$. The supernatant was poured though a 20-mesh sieve $(0.833-\mathrm{mm}$ openings) sitting on a 500-mesh sieve (0.025-mm openings). This procedure was repeated twice. Leaf material on the 20-mesh sieve was placed in a water-filled petri dish. Forceps were used to remove adhering soil, and the leaf material was placed in glass vial, heated at $70^{\circ} \mathrm{C}$ until dry, and then weighed, after which loss of dry mass was calculated. In calculating mass loss in this way, I recognized that some leaf material could pass through the 20mesh sieve without being decomposed, but I assumed that differences in leaf mass retained on the sieve reflected relative differences in decomposition rates. The material on the 500-mesh sieve was transferred to a Baermann funnel, and nematodes were collected after $48 \mathrm{~h}$. After the total number of nematodes was determined, the entire suspension was centrifuged. The nematode pellet, in $\approx 0.1 \mathrm{ml}$ of fluid, was transferred to a glass microscope slide and gently heated to immobilize nematodes. After being covered with a 22-by-50-mm coverslip, the nematodes were examined at $\times 400$ magnification. The first 30 nematodes encountered were identified to trophic group based on mouth and esophagus morphology (41).

There were six replicate vials for each heat treatment. The experiment was performed once with soil collected in spring and once with soil collected in fall.

Effect of nematodes on the response of $D$. candidum to alfalfa leaves (experiment 2). Experiment 2 determined whether the response of $D$. candidum to alfalfa required nematodes. Soil that was either nonheated or heated in a $50^{\circ} \mathrm{C}$ oven for $5 \mathrm{~h}$ was packed into vials as described for experiment 1 . The soil contained 0 or $72 \mathrm{mg}$ of alfalfa leaves and zero or five nematodes parasitized by $D$. candidum (the parasitized nematode is a useful and important form of inoculum for $D$. candidum and other nematophagous fungi) (17). To obtain parasitized nematodes, 1,000 infective juveniles of the entomopathogenic nematode Steinernema glaseri were added to cultures of $D$. candidum (ATCC 204099). Infective juveniles of $S$. glaseri were obtained from wax moth larvae (28). Before the nematodes were added, the fungus, which produces a small number of adhesive knobs on agar when 
nematodes are absent but many more when they are present, had been growing on quarter-strength corn meal agar (CMA/4) in a 10 -cm-diameter petri dish for 15 days at $20^{\circ} \mathrm{C}$. Three days after they were added, nearly all the $S$. glaseri had been killed and colonized by the fungus. A pick was used to transfer individual colonized $S$. glaseri from the culture to the soil before the soil was added to the vial. In summary, the experiment had two levels of soil heating (none or $5 \mathrm{~h}$ at $\left.50^{\circ} \mathrm{C}\right)$, two levels of alfalfa $(0$ or $72 \mathrm{mg}$ ), and two levels of $D$. candidum (zero or five colonized nematodes).

After 28 days at $20^{\circ} \mathrm{C}$, the soil from each vial was placed in a beaker and mixed. To quantify the propagule density of nematode-trapping fungi, $10 \mathrm{~g}$ (dry weight equivalent) of soil was placed in a sterile 125 -ml flask, and its volume was increased to $50 \mathrm{ml}$ with sterile distilled water. After the suspension was shaken for $8 \mathrm{~min}$, a 10-fold dilution series was prepared, but with only two dilutions. Each of five CMA/4 plates received $0.1 \mathrm{ml}$ (containing $\approx 0.020$ or $0.002 \mathrm{~g}$ of soil) from each dilution, and bait nematodes (healthy infective juveniles of $S$. glaseri) were added as described before (18). After 3 weeks at room temperature, the plates were examined with a dissecting microscope $(\times 40$ to $\times 70$ magnification) and scored for the presence and absence of D. candidum and other nematode-trapping fungi. Fungi were identified to species based on trap, conidiophore, and conidium morphology (9). The presence or absence data were converted to a quantitative estimate of propagule density by using a most probable number program (29).

To quantify nematodes, $10 \mathrm{~g}$ (dry weight equivalent) of soil from each vial was placed on a Baermann funnel, and nematodes were collected, counted, and identified to trophic group as described in experiment 1 .

There were nine replicate vials for each treatment. The experiment was performed once with soil collected in summer and once with soil collected in winter.

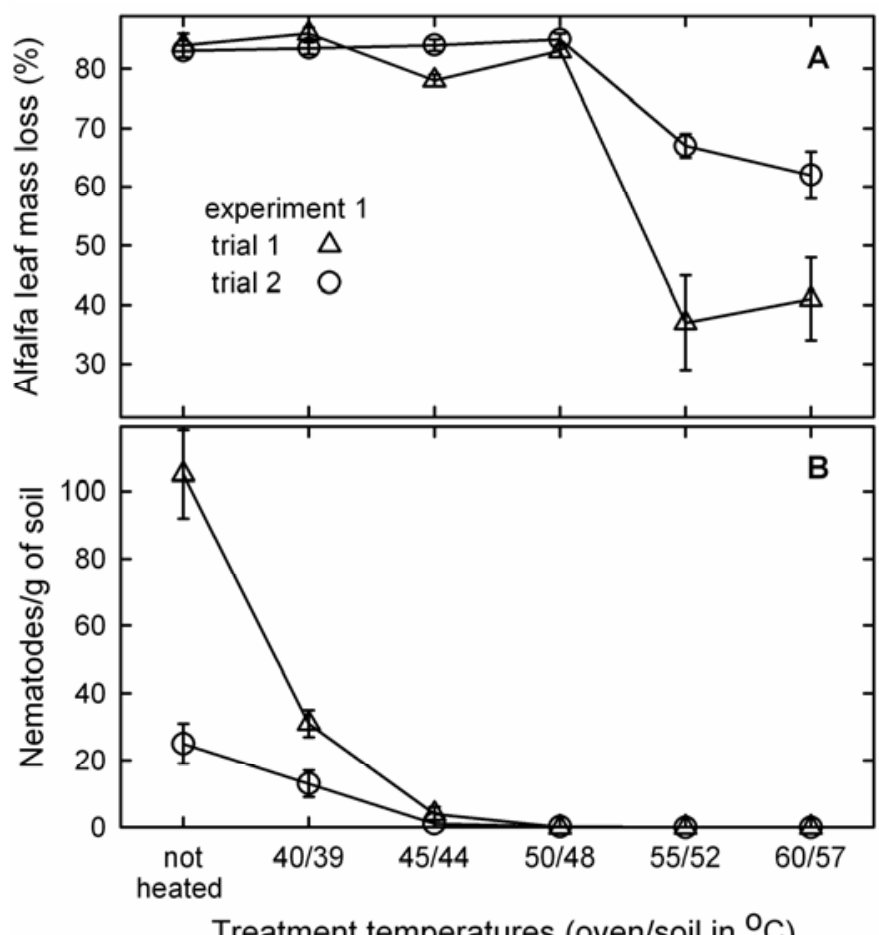

Fig. 1. Effect of heat treatment of soil on mass loss of alfalfa leaves and nematodes (experiment 1). Soil was either not heated or heated for $5 \mathrm{~h}$ at different temperatures, amended with alfalfa leaves, packed into vials, and incubated for 28 days at $20^{\circ} \mathrm{C}$. Temperatures on the $x$ axis indicate the oven temperature and the soil temperature for the last $3 \mathrm{~h}$ of heat treatment. Values are the means plus or minus one standard error of six replicate vials.
Effect of nematodes and reduced microbial competition on the response of $D$. candidum to alfalfa leaves (experiment 3 ). In addition to repeating parts of experiment 2 , experiment 3 determined whether $D$. candidum could use alfalfa in the absence of nematodes if saprophytic competition was reduced. This experiment included three levels of heat treatment (none, $5 \mathrm{~h}$ at $50^{\circ} \mathrm{C}$, or $5 \mathrm{~h}$ at $60^{\circ} \mathrm{C}$ ), two levels of alfalfa ( 0 or $72 \mathrm{mg}$ ), and only one level of $D$. candidum (five colonized nematodes). The controls without D. candidum were excluded because experiment 2 demonstrated that site 4 soil contained no $D$. candidum and only small numbers of other nematode-trapping fungi. Soil was packed into vials, incubated, and assayed as described for experiment 2.

There were nine replicates for each of the six treatments. The experiment was performed once with soil collected in winter and once with soil collected in spring.

Time-course study (experiment 4). This experiment determined whether $D$. candidum reduced nematode numbers in alfalfaamended soil and whether increases and decreases in D. candidum numbers followed increases and decreases in nematode numbers. The effect of $D$. candidum on nematode numbers also was part of experiment 2 , but experiment 2 data were collected only on day 28; experiment 4 considered whether $D$. candidum affected nematodes before or after day 28. Each vial received nonheated soil containing $72 \mathrm{mg}$ of alfalfa leaves and zero or five $S$. glaseri colonized by $D$. candidum. After $0,5,14,22,36,53$, 69 , and 84 days at $20^{\circ} \mathrm{C}$, nine vials for each of the two treatments (plus or minus $D$. candidum) were destructively sampled and assayed as described in experiment 2. Additional vials were destructively sampled at day 28 and 60 to determine soil water content. The small losses in soil water were corrected by adding distilled water to the remaining vials. The experiment was performed twice, and the second trial was identical to the first except for minor differences in sampling days. Soil for both trials was collected in spring.

Response of $D$. candidum to nematodes in the absence of alfalfa leaves (experiments $5 \mathbf{a}$ and $5 \mathbf{b}$ ). Experiments $5 \mathrm{a}$ and $5 \mathrm{~b}$ compared the response of $D$. candidum and two other nematophagous fungi to additions of nematodes in the absence of alfalfa leaves. The two other fungi were Arthrobotrys oligospora and H. rhossiliensis. A. oligospora (isolated from soil dilution plates in experiment 4 , laboratory designation $=191$ ) produces adhesive networks and is considered a good saprophyte but a poor parasite relative to the other nematode-trapping fungi (7). The endoparasitic fungus $H$. rhossiliensis (isolated from a peach orchard in South Carolina; ATCC 46487) produces adhesive conidia and is a poor saprophyte but a good parasite (23). S. glaseri colonized by these fungi were obtained as described for experiment 2 , except that nematodes were added on day -1.5 to 5 -day-old colonies of A. oligospora or on day -3.5 to 40-day-old colonies of $H$. rhossiliensis (the latter fungus grows much more slowly than the former). Rates of radial extension for colonies growing on CMA $/ 4$ at $20^{\circ} \mathrm{C}$ were $0.7,3.0$, and $4.5 \mathrm{~mm}$ /day for $H$. rhossiliensis, D. candidum, and A. oligospora, respectively.

Because $H$. rhossiliensis cannot easily be quantified by the dilution plating or most probable number procedure but can be quantified by bioassay (20), and because the opposite is true for A. oligospora $(18,24)$, the experiment was divided into two parts, $5 \mathrm{a}$ and $5 \mathrm{~b}$. Experiment 5a compared parasitism of assay nematodes by $D$. candidum and $H$. rhossiliensis. On day 0 , vials were packed with nonheated soil containing zero or five $S$. glaseri colonized by $D$. candidum or $H$. rhossiliensis. On day 14,28 , and 42,0 or 20 host nematodes (healthy infective-stage juveniles of $S$. glaseri) in $0.1 \mathrm{ml}$ of $2 \mathrm{mM} \mathrm{KCl}$ were added to each vial. Although the number of healthy hosts added was small, the biomass of these healthy hosts was substantial because infective juveniles of $S$. glaseri are large (17). In summary, experiment 5a had three kinds of fungi (none, D. candidum, or H. rhossiliensis), two levels of host nematode addition ( 0 or 20 added three times), and nine 
replications of each of the six combinations. On day $63, \approx 620$ assay nematodes (second-stage juveniles [J2] of the root-knot nematode Meloidogyne javanica) were added to each vial in $0.25 \mathrm{ml}$ of $2 \mathrm{mM} \mathrm{KCl}$. To obtain $M$. javanica J2, eggs from infected greenhouse tomato plants (13) were placed on Baermann funnels; J2 were collected after $48 \mathrm{~h}$ and were not stored before addition to soil. After $24 \mathrm{~h}$ at $20^{\circ} \mathrm{C}$, nematodes were extracted from the soil in each vial by centrifugation in water and then in a sucrose solution $(27) ; 25-\mu \mathrm{m}$ sieves were used. The nematode suspension was mixed, and 1/10th was pipetted into a dish; all of the assay nematodes in the dish were transferred individually to a drop of water on a glass microscope slide and examined at $\times 140$ magnification with a dissecting microscope. The number of assay nematodes in the dish and the number with and without adhering conidia of $H$. rhossiliensis or knobs of $D$. candidum were determined. An additional sample was examined as needed to ensure that at least 50 assay nematodes per replicate were examined for the presence or absence of adhering conidia or knobs. Experiment $5 \mathrm{~b}$ was identical to 5a except that $A$. oligospora replaced $H$. rhossiliensis and the dilution plating or most probable number procedure replaced the bioassay.

I predicted that addition of healthy $S$. glaseri would increase the percentage of assay nematodes ( $\mathrm{J} 2$ of $M$. javanica) parasitized by both $H$. rhossiliensis and $D$. candidum in experiment $5 \mathrm{a}$ and increase the propagule density of $D$. candidum but not $A$. oligospora in experiment $5 \mathrm{~b}$. Experiments $5 \mathrm{a}$ and $5 \mathrm{~b}$ were performed once.

Statistical analysis. For experiment 1 , inferences about nematode numbers were based on examination of means and variances whereas mass loss data were subjected to an analysis of variance, using treatment temperature as a categorical variable and Duncan's multiple range test to separate means. For the other experiments, data on nematode number and fungus propagule density were log transformed before being subjected to factorial analysis using the GLM procedure of SAS. Parasitism data in experiment 5 were arcsine transformed before analysis. For experiments 2 and 3, the most important analysis determined whether there was a statistical interaction between the effects of heat treatment and alfalfa on D. candidum propagule density; because this interaction was always significant, means of individual treatments were compared using Duncan's multiple range test. Although trials within an experiment generally produced similar results, the results were sufficiently different to prevent averaging between trials.

\section{RESULTS}

Effect of heat treatment on nematodes and litter mass loss (experiment 1). When placed in the oven, soil temperature increased relatively rapidly for $\approx 2 \mathrm{~h}$ and then increased gradually for $3 \mathrm{~h}$ to a temperature that was 1 to $3^{\circ} \mathrm{C}$ less than that of the oven air temperature. When the oven setting and air temperatures were $40,45,50,55$, or $60^{\circ} \mathrm{C}$, the mean soil temperatures for the last $3.0 \mathrm{~h}$ in the oven were $39,44,48,52$, or $57^{\circ} \mathrm{C}$, respectively.

Mass loss of alfalfa leaves exceeded $75 \%$ in nonheated soil and was not affected $(P>0.05)$ by heating soil to 39,44 , or $48^{\circ} \mathrm{C}$ (Fig. 1A). Mass loss, however, was reduced by heating soil to 52 or $57^{\circ} \mathrm{C}$ (Fig. 1A). Reductions in mass loss caused by heating soil to 52 or $57^{\circ} \mathrm{C}$ were greater in trial 1 than in trial 2 .
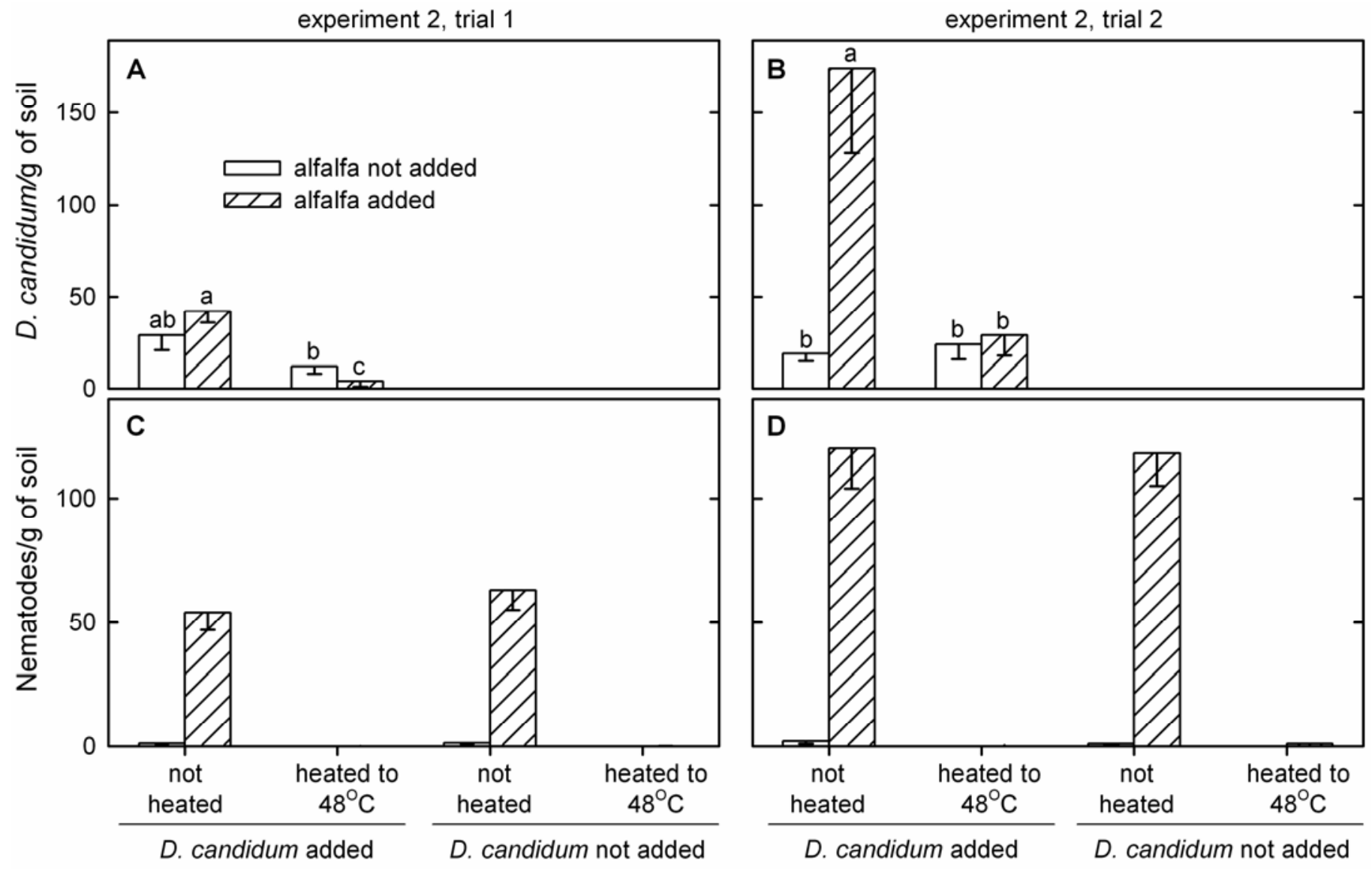

Heat treatment of soil and addition of $D$. candidum

Fig. 2. Effect of Dactylellina candidum, alfalfa leaves, and heating of soil to $48^{\circ} \mathrm{C}$ on numbers of $D$. candidum propagules and soil nematodes (experiment 2). Soil was either not heated or heated to $48^{\circ} \mathrm{C}$, amended with alfalfa leaves, infested with $D$. candidum or not, packed into vials, and incubated for 28 days at $20^{\circ} \mathrm{C}$. Values are the means minus one standard error of nine replicate vials. In the top two panels, bars with the same letter are not significantly different $(P>0.05)$. 
Nematodes, which were much more numerous in trial 1 than in trial 2, were eliminated by heating soil to $48^{\circ} \mathrm{C}$ and nearly eliminated by heating soil to $44^{\circ} \mathrm{C}$ (Fig. 1B). The surviving nematodes in soil heated to $44^{\circ} \mathrm{C}$ were all one species of fungivore, probably Aphelenchus avenae.

Effect of nematodes on the response of $D$. candidum to organic amendment (experiment 2). D. candidum was not detected in soil to which it was not added (Fig. 2A and B). In soil infested with $D$. candidum, the statistical interaction between heating of soil to $48^{\circ} \mathrm{C}$ and addition of alfalfa was significant (i.e., addition of alfalfa tended to increase $D$. candidum numbers in nonheated soil but not in $48^{\circ} \mathrm{C}$-treated soil; the increase was much greater in trial 2 than in trial 1) (Fig. 2A and B). Other nematodetrapping fungi were detected in small numbers $(<3$ propagules/g of soil) in nonheated soil amended with alfalfa but not in the other treatments (data not shown).

Heating soil to $48^{\circ} \mathrm{C}$ eliminated nematodes from all replicates of trial 1 (Fig. 2C) and all but three replicate vials of trial 2 (Fig. 2D), which contained very small numbers of fungivores or bacterivores. In nonheated soil, addition of alfalfa greatly increased nematode numbers; fungivores (species of Aphelenchus, Aphelenchoides, and Tylopharynx) represented $\approx 40 \%$ of the nematodes, and bacterivores (mostly Cephalobidae) represented $\approx 60 \%$, whether D. candidum was added or not. Addition of D. candidum did not reduce nematode numbers (Fig. 2C and D).

Effect of nematodes and reduced microbial competition on the response of $D$. candidum to organic amendment (experiment 3). As in experiment 2, there was a significant interaction between heating of soil and addition of alfalfa (i.e., D. candidum propagule density tended to increase if alfalfa was added to nonheated soil or to soil heated to $57^{\circ} \mathrm{C}$ ) (Fig. $3 \mathrm{~A}$ and $\mathrm{B}$ ) but tended to decrease if alfalfa was added to soil heated to $48^{\circ} \mathrm{C}$ (Fig. $3 \mathrm{~A}$ and B).

Nematodes were not detected in $57^{\circ} \mathrm{C}$-treated soil and were detected in very small numbers and in only a few replicates containing $48^{\circ} \mathrm{C}$-treated soil (Fig. $3 \mathrm{C}$ and D). As in experiment 1 , all nematodes detected in $48^{\circ} \mathrm{C}$-treated soil were similar to $A$. avenae. Nematode numbers increased greatly when alfalfa was added to nonheated soil; however, the nematode communities differed in trial 1 versus trial 2 . Of the nematodes in nonheated soil amended with alfalfa, $69 \%$ were fungivores and $31 \%$ bacterivores (mostly Cephalobidae) in trial 1, but $23 \%$ were fungivores and $76 \%$ were bacterivores (mostly Rhabditidae) in trial 2.

Time-course study (experiment 4). In experiment 4, in which all vials contained nonheated soil amended with alfalfa leaves, nematodes increased to large numbers whether or not D. candi$d u m$ had been added (Fig. 4A and B). In trial 1, numbers were similar in D. candidum and control soil for all sample times (Fig. 4A). In trial 2, numbers were smaller in D. candidum vials on days 36 and 52 but greater in D. candidum vials on day 86 (Fig. 4B). D. candidum caused no consistent differences in the percentages or population densities of bacterivores (mostly Rhabditidae and Cephalobidae) or fungivores (mostly Aphelenchus, Aphelenchoides, and Tylopharynx spp.). In trial 2, the smaller nematode numbers in $D$. candidum vials on days 36 and 52 were associated with a nonsignficant reduction in the population density of Cephalobidae. Correlations between D. candidum propagule density and nematode numbers were not significant whether nematodes were expressed as population densities or percentages of all nematodes by trophic group (bacterivore or fungivore) or taxonomic group (Rhabditidae, Cephalobidae, Aphelenchus, Aphelenchoides, or Tylopharynx spp.).
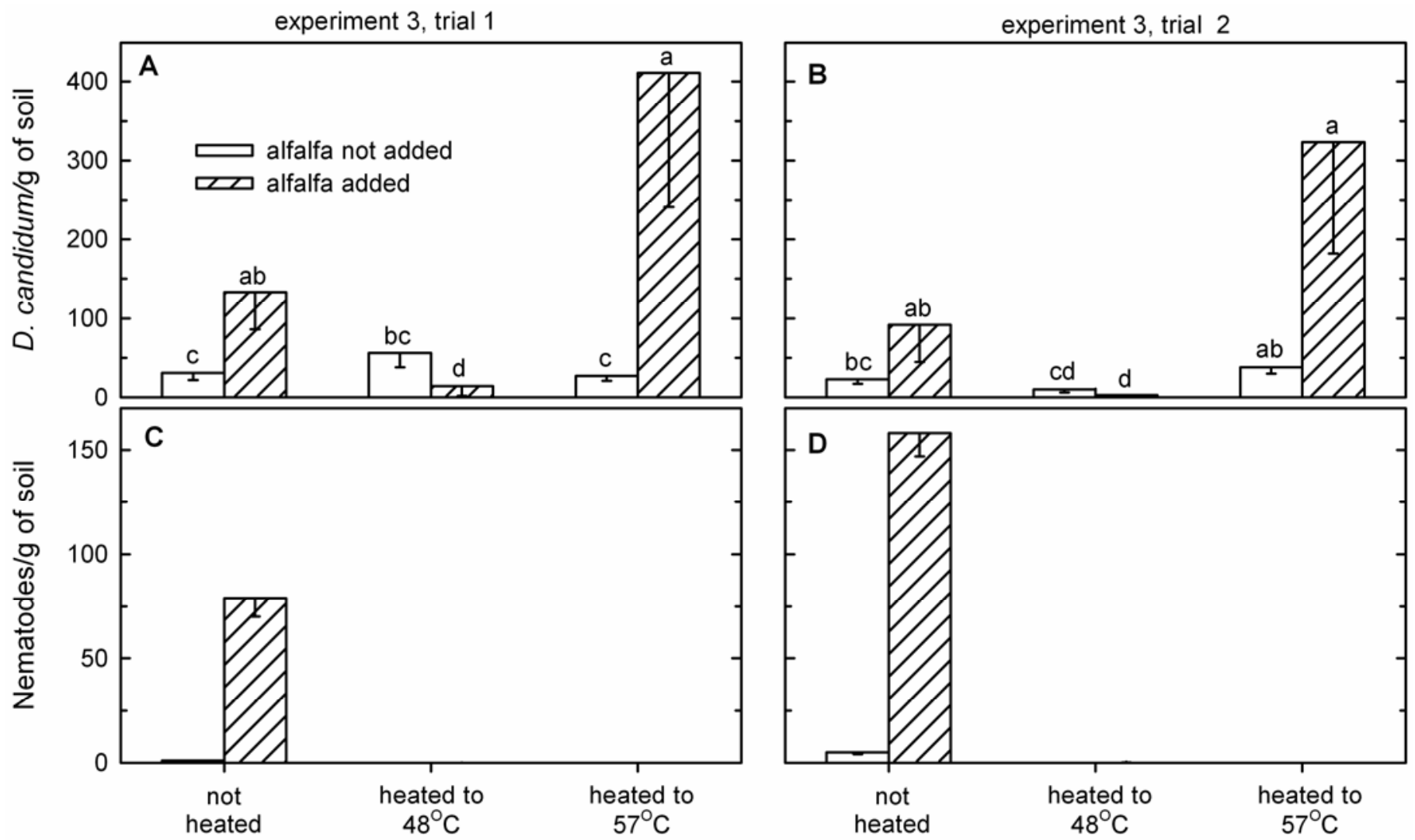

Heat treatment of soil

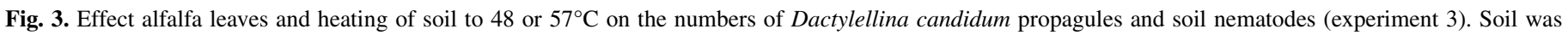

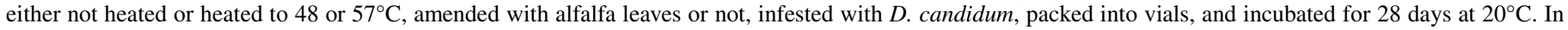

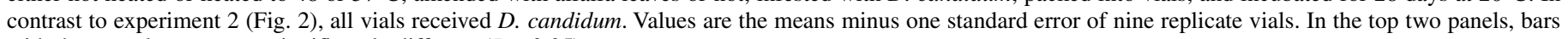
with the same letter are not significantly different $(P>0.05)$. 
Bacterivores usually made up 65 to $80 \%$ of all nematodes in experiment 4 . The initial increase in nematode numbers largely consisted of Rhabditidae, but Cephalobidae became abundant after day 36. Fungivores increased more slowly than did bacterivores but made up $\approx 30 \%$ of the total nematodes by day 36 and thereafter (Fig. 4C and D). Numbers of fungivorous nematodes were smaller in D. candidum vials on day 53 in trial 1 and day 36 in trial 2. Plant parasites, predators, and omnivores represented $<10 \%$ of the nematodes.

In vials infested with $D$. candidum, the fungus rapidly increased, peaked after 2 to 3 weeks, and then declined, even though nematode numbers continued to increase (Fig. 4E and F). Large variances on day 84 of trial 1 and day 22 of trial 2 resulted from unusually large numbers of $D$. candidum in one or two of the nine replicate vials. $D$. candidum was not detected in control vials, except on day 84 in trial 1 (D. candidum was detected in two vials) and on day 52 of trial 2 (D. candidum was detected in one vial).
Other nematophagous fungi detected included those that form adhesive networks (Arthrobotrys oligospora, A. eudermata, A. thaumasia, and $A$. superba) and a Nematoctonus sp.; numbers of these other nematophagous fungi were relatively small and similar in soil infested or not infested with D. candidum (Fig. 4G and $\mathrm{H}$ ).

Enchytraeids were detected on the fungal dilution plates in $\approx 10 \%$ of the samples. When detected, population densities were seldom $>10$ individuals/g of soil (data not shown).

Response of $D$. candidum to nematodes in the absence of organic amendment (experiment 5a and 5b). In experiment 5a, the extraction efficiency for assay nematodes ( $M$. javanica $\mathrm{J} 2$ ) was high $(\approx 55 \%$ overall $)$ and was unaffected by fungus or addition of host nematodes except possibly in the case of $H$. rhossiliensis, where extraction efficiency was $62 \%$ if host nematodes were not added and $51 \%$ if they were $(P=0.055)$.

In control vials, only a few assay nematodes had adhering knobs and none had adhering spores (Fig. 5A). Adhering knobs

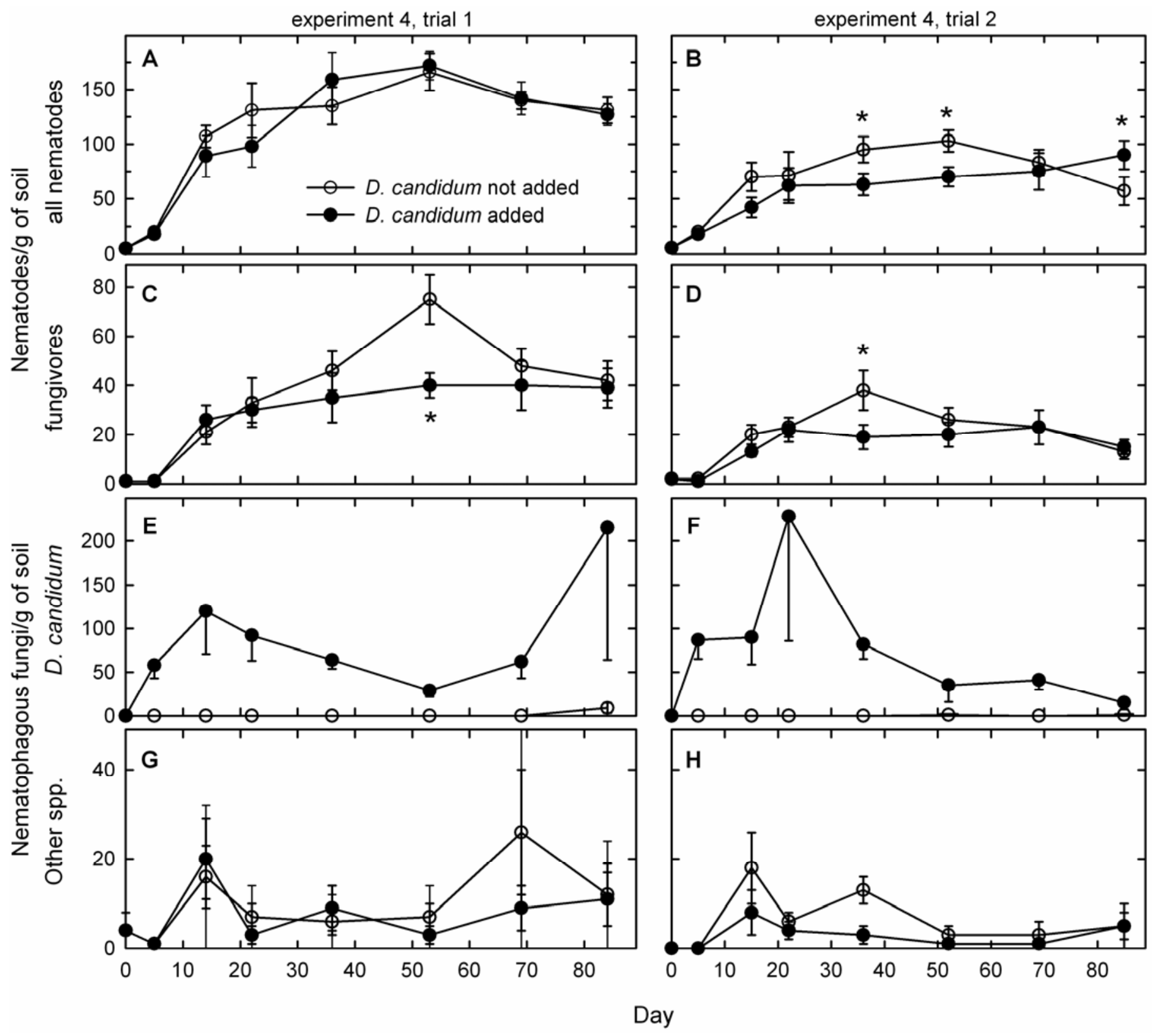

Fig. 4. Numbers of nematodes and nematode-trapping fungi in the time-course study (experiment 4). Nonheated soil was amended with alfalfa leaves, infested or not with Dactylellina candidum, packed into vials, and incubated at $20^{\circ} \mathrm{C}$ for 5 to 85 days. Values are the means plus or minus one standard error (or minus one standard error for $D$. candidum propagule density) of nine replicate vials. An asterisk indicates that the nematode numbers for that sampling time were significantly different $(P<0.05)$ in soil with and without $D$. candidum. 
were distinguishable from adhering spores because the knobs were rounder and had thinner cell walls than the spores. In vials infested with $H$. rhossiliensis, addition of host nematodes increased the percentage of assay nematodes with adhering spores (Fig. 5A), but the difference was only marginally significant $(P=$ $0.056)$. In vials infested with $D$. candidum, addition of host nematodes significantly increased $(P=0.0009)$ the percentage of assay nematodes with adhering knobs (Fig. 5A).

In experiment $5 \mathrm{~b}$, the propagule density of $D$. candidum but not of A. oligospora increased if host nematodes were added to soil
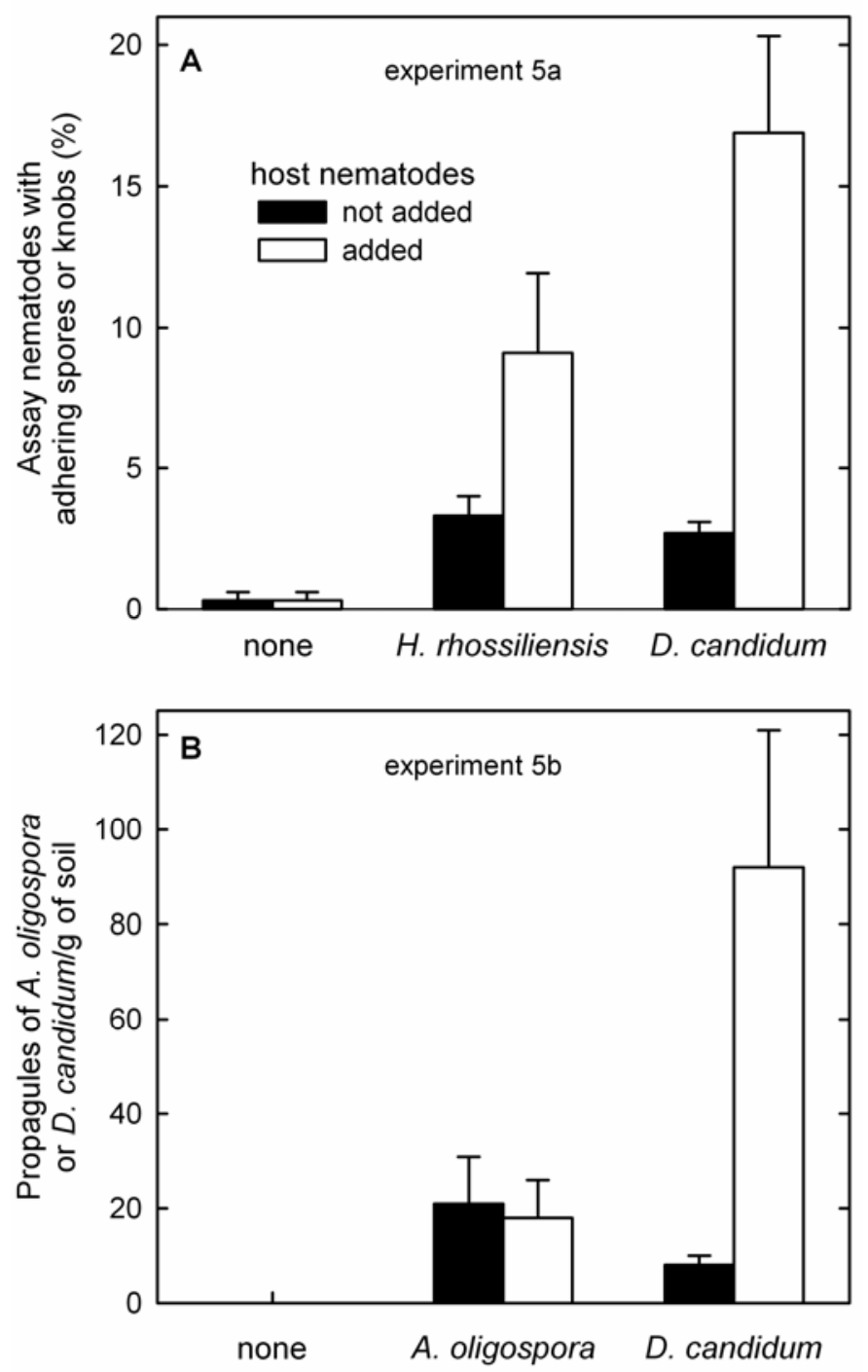

Fungus added

Fig. 5. Effect of adding healthy host nematodes on Dactylellina candidum and Hirsutella rhossiliensis activity (experiment 5a) and on D. candidum and Arthrobotrys oligospora propagule density (experiment $5 \mathrm{~b}$ ). Nonheated soil (infested with $D$. candidum, $H$. rhossiliensis, A. oligospora, or not infested) was packed into vials, kept at $20^{\circ} \mathrm{C}$, and inoculated with 0 or 20 healthy host nematodes (Steinernema glaseri) on day 14,28 , and 42 . On day $63, D$. candidum and $H$. rhossiliensis parasitic activities (experiment 5a) or D. candidum and A. oligospora propagule densities (experiment $5 b$ ) were quantified. In experiment 5a, assay nematodes (healthy juveniles of Meloidogyne javanica) were added to soil, recovered after $24 \mathrm{~h}$, and examined for adhering knobs of D. candidum or adhering spores of $H$. rhossiliensis. In treatments receiving D. candidum, assay nematodes with adhesive spores were not observed. Similarly, in treatments receiving $H$. rhossiliensis, assay nematodes with adhesive knobs were not observed. In experiment 5 b, fungal propagule densities were determined by serial dilution, baiting, and most probable number procedures. D. candidum and A. oligospora were detected only in vials to which they had been added. Values in both experiments are the means plus one standard error of nine replicate vials.
(Fig. 5B). These fungi were detected only in vials to which they had been added. No nematophagous fungi were observed in control vials, and no other nematophagous fungi were observed in any vial.

\section{DISCUSSION}

The purpose of this study was to clarify why the nematodetrapping fungus $D$. candidum increases when crop residues (alfalfa leaves) are added to soil. Several explanations were possible at the outset. One possible explanation was that the fungus might be quite saprophytic, directly using dead alfalfa leaves and not requiring nematodes at all. Another was that the fungus might lack saprophytic activity and might depend completely on nematodes. Finally, the fungus might require or be able to use both dead alfalfa leaves and living nematodes. Because D. candidum produces adhesive knobs, and fungi that form adhesive knobs are thought to be poor saprophytes $(25,26)$, I predicted that the fungus would not respond to alfalfa leaves when nematodes were absent and saprophytic competition was normal.

Maintaining saprophytic competition in these experiments was essential because even a very weak competitive saprophyte, like the nematophagous fungus $H$. rhossiliensis, will grow saprophytically if competition is unrealistically reduced (23). To eliminate nematodes without reducing saprophytic competition, I used a destructive rather than a constructive approach (12) (i.e., I attempted to selectively eliminate nematodes from a complex soil community rather than selectively add nematodes and other organisms to a soil that was initially sterilized or simplified by irradiation, fumigation, and so on) (3). Heat was used because it is easily controlled and because nematodes generally are sensitive to heat treatment.

The intensity of saprophytic competition was inferred from rates of litter mass loss, a saprophytic process that integrates the effects of many different organisms and is relatively easy to measure. It seemed reasonable to assume that competition for alfalfa leaves was normal or at least substantial if a heat treatment did not reduce the rate of litter mass loss. But, that assumption must be recognized as a limitation of this study: heat could change the microbial community and perhaps change competition without changing the rate of litter mass loss. Because heating soil to $48^{\circ} \mathrm{C}$ apparently did not reduce saprophytic competition for alfalfa leaves but almost always eliminated nematodes, that temperature was used in the soil heating experiments.

The results indicated that the response of $D$. candidum to alfalfa leaves depends on consumption of nematodes. First, D. candidum numbers did not increase in alfalfa-amended soil exhibiting normal levels of saprophytic competition but containing no nematodes (the soil had been heated to $48^{\circ} \mathrm{C}$ ). Second, D. candidum numbers did increase when nematodes without alfalfa leaves were added to nonheated soil. Although indicating that nematodes are essential, these results do not exclude the possibility that $D$. candidum may simultaneously consume living nematodes and dead organic matter. Determining whether $D$. candidum directly uses any dead organic matter will probably require the careful tracking of a label, which was not done in this study.

Although $D$. candidum could not use alfalfa leaves in the absence of nematodes when saprophytic competition was normal (in $48^{\circ} \mathrm{C}$-treated soil), the fungus apparently could use the leaves in the absence of nematodes when saprophytic competition was reduced by heating soil to $57^{\circ} \mathrm{C}$. This result could be considered as evidence that $D$. candidum sometimes can behave saprophytically in soil, or the result could be considered an artifact. I support the latter interpretation because saprophytic competition in moist, nontreated soil is probably fierce and, as stated before, even weak saprophytes may grow saprophytically in artificially simplified communities (23). The increase of $D$. candidum in $57^{\circ} \mathrm{C}$-treated soil also indicates that the failure of $D$. candidum to 
increase in $48^{\circ} \mathrm{C}$-treated soil did not result from the degradation of the chemical or physical environment.

Given that knob-forming fungi already were thought to be more parasitic than saprophytic fungi $(25,26)$, most results in this study were expected. But, those from the time-course study were not. In that experiment, nematode and fungus numbers were quantified over time in alfalfa-amended soil, and I had anticipated and hoped that $D$. candidum and nematodes would exhibit classical, predator-prey population dynamics (8), perhaps like those exhibited by lynx and snowshoe hare (30). In other words, I expected that the fungus would "track" nematode numbers (that D. candidum numbers would increase and decrease following increases and decreases in nematodes) and that $D$. candidum would suppress nematodes. There was little evidence for any of this.

Lack of consistent nematode suppression in the time-course study might be explained by the rapid birth rates of fungivorous and, especially, bacterivorous nematodes, such that increased nematode birth (resulting from decreased competition among nematodes) compensated for increased nematode mortality. A better explanation, however, is that $D$. candidum numbers remained too small to suppress nematodes. In previous studies, D. candidum consistently parasitized $>50 \%$ of assay nematodes only when its propagule density exceeded $1,000 / \mathrm{g}$ of soil $(18,19)$. In the current study, $D$. candidum propagule density seldom exceeded $100 /$ g of soil.

Not only did $D$. candidum numbers remain relatively small but, after initially increasing, the numbers declined while nematode numbers continued to increase (i.e., the fungus failed to track its prey). The failure of certain other nematode-trapping fungi to track nematodes has been reported previously by Cooke $(5,6)$, who inferred that the fungi, which were mostly net formers in his soil, were primarily saprophytes that trapped nematodes only during the initial stages of decomposition. To explain the results of the current time-course study, one could invoke Cooke's explanation $(D$. candidum increases as it consumes both fresh litter and nematodes but then declines as the litter ages) or one could consider some alternatives. For example, after initially increasing, perhaps $D$. candidum was suppressed by fungivorous nematodes. Fungivorous nematodes were abundant in soil amended with alfalfa leaves, and several studies have demonstrated that fungivorous nematodes consume and suppress various nematodetrapping fungi on agar $(10,35)$ and plant-pathogenic fungi in soil $(11,14)$. Other kinds of fungivores were not quantified in this study but also could be important.

Another possible explanation for the failure of $D$. candidum to track total nematode numbers is that some nematode species in site 4 soil may not have been susceptible to $D$. candidum, and the fungus may have been tracking only an unknown subset of nematode species. Although researchers usually assume that most nematodes are susceptible to most trapping fungi, there is some reason to suspect that susceptibility varies $(4,15)$. The host or prey range of $D$. candidum among nematodes is largely unknown.

It follows that expecting a nematode-trapping fungus and nematodes to behave like lynx and hare may be naive. Even if D. candidum behaves like a lynx, in that the fungus may consume only prey nematodes and not litter, the potential for some of the prey nematodes to consume the fungus (which would be analogous to the potential for some hares to consume lynx) and the possibility that some nematode species are not susceptible would obviously complicate the predator-prey dynamics. These potential complexities, along with all of the other biotic and abiotic complexities of soil systems, justify some discouragement: Will we ever understand how nematode-trapping fungi regulate or fail to regulate nematode populations in soil? But, even the lynx-hare interaction required many decades to elucidate (30), and those of us who work with trapping fungi and nematodes should not be deterred by slow progress. Many useful and interesting questions remain. For example, does $D$. candidum attack most, many, or only a few of the nematode species in site 4 soil, and does fungivory explain the failure of $D$. candidum to track nematode numbers?

\section{LITERATURE CITED}

1. Barron, G. L. 1977. The Nematode-Destroying Fungi. Canadian Biological Publications, Guelph, Ontario, Canada.

2. Barron, G. L. 1992. Lignolytic and cellulolytic fungi as predators and parasites. Pages 311-326 in: The Fungal Community: Its Organization and Role in the Ecosystem. G. C. Carroll and D. T. Wicklow, eds. Marcel Dekker, New York.

3. Boogert, P. H. J. F., van den Velvis, H., Ettema, C. H., and Bouwman, L. A. 1994. The role of organic matter in the population dynamics of the endoparasitic nematophagous fungus Drechmeria coniospora in microcosms. Nematologica 40:249-257.

4. Bouwman, L. A., Hoenderboom, G. H. J., van der Maas, K. J., and de Ruiter, P. C. 1996. Effects of nematophagous fungi on numbers and death rates of bacterivorous nematodes in arable soil. J. Nematol. 28:26-35.

5. Cooke, R. C. 1962. The behavior of nematode-trapping fungi during decomposition of organic matter in the soil. Trans. Br. Mycol. Soc. 45:314-320.

6. Cooke, R. C. 1962. The ecology of nematode-trapping fungi in the soil. Ann. Appl. Biol. 50:507-513.

7. Cooke, R. C. 1963. Ecological characteristics of nematode-trapping hyphomycetes. I. Preliminary studies. Ann. Appl. Biol. 52:431-437.

8. Cooke, R. 1968. Relationships between nematode-destroying fungi and soil-borne phytonematodes. Phytopathology 58:909-913.

9. Cooke, R. C., and Godfrey, B. E. S. 1964. A key to the nematode-destroying fungi. Trans. Br. Mycol. Soc. 47:61-74.

10. Cooke, R. C., and Pramer, D. 1968. Interactions of Aphelenchus avenae and some nematode-trapping fungi in dual culture. Phytopathology 58:659-661.

11. Friberg, H., Lagerlöf, J., and Rämert, B. 2005. Influence of soil fauna on fungal plant pathogens in agricultural and horticultural systems. Biocontrol Sci. Technol. 15:641-658.

12. Griffiths, B. S., Ritz, K., Bardgett, R. D., Cook, R., Christensen, S., Ekelund, F., Sorensen, S. J., Baath, E., Bloem, J., De Ruiter, P. C., Dolfing, J., and Nicolardot, B. 2000. Ecosystem response of pasture soil communities to fumigation-induced microbial diversity reductions: an examination of the biodiversity-ecosystem function relationship. Oikos 90:279-294.

13. Hussey, R. S., and Barker, K. R. 1973. A comparison of methods of collecting inocula of Meloidogyne spp., including a new technique. Plant Dis. Rep. 57:1025-1028.

14. Ishibashi, N., and Choi, D. R. 1991. Biological-control of soil pests by mixed application of entomopathogenic and fungivorous nematodes. $\mathrm{J}$. Nematol. 23:175-181.

15. Jaffee, B. A. 1998 Susceptibility of a cyst and a root-knot nematode to three nematode-trapping fungi. Fundam. Appl. Nematol. 21:695-703.

16. Jaffee, B. A. 1999. Enchytraeids and nematophagous fungi in tomato fields and vineyards. Phytopathology 89:398-406.

17. Jaffee, B. A. 2000. Augmentation of soil with the nematophagous fungi Hirsutella rhossiliensis and Arthrobotrys haptotyla. Phytopathology 90:498-504.

18. Jaffee, B. A. 2003. Correlations between most probable number and activity of nematode-trapping fungi. Phytopathology 93:1599-1605.

19. Jaffee, B. A. 2004. Do organic amendments enhance the nematodetrapping fungi Dactylellina haptotyla and Arthrobotrys oligospora? J. Nematol. 36:267-275.

20. Jaffee, B. A., and Muldoon, A. E. 1995. Numerical responses of the nematophagous fungi Hirsutella rhossiliensis, Monacrosporium cionopagum, and M. ellipsosporum. Mycologia 87:643-650.

21. Jaffee, B., Phillips, R., Muldoon, A., and Mangel, M. 1992. Density-dependent host-pathogen dynamics in soil microcosms. Ecology 73:495-506.

22. Jaffee, B. A., and Tedford, E. C., Muldoon, A. E. 1993. Tests for densitydependent parasitism of nematodes by nematode-trapping and endoparasitic fungi. Biol. Control 3:329-336.

23. Jaffee, B. A., and Zehr, E. I. 1985. Parasitic and saprophytic ability of the fungus Hirsutella rhossiliensis. J. Nematol. 17:341-345.

24. Jansson, H. B. 1982. Predacity by nematophagous fungi and its relation to the attraction of nematodes. Microb. Ecol. 8:233-240.

25. Jansson, H. B., and Nordbring-Hertz, B. 1979. Attraction of nematodes to living mycelium of nematophagous fungi. J. Gen. Microbiol. 112:89-93.

26. Jansson, H. B., and Nordbring-Hertz, B. 1980. Interactions between nematophagous fungi and plant-parasitic nematodes: Attraction, induction of trap formation and capture. Nematologica 26:383-389.

27. Jenkins, W. R. 1964. A rapid centrifugal-flotation technique for separating nematodes from soil. Plant Dis. Rep. 48:692. 
28. Kaya, H. K., and Stock, S. P. 1997. Techniques in insect nematology. Pages 281-324 in: Manual of Techniques in Insect Pathology. L. Lacey, ed. Academic Press, San Diego, CA.

29. Klee, A. J. 1993. A computer program for the determination of most probable number and its confidence limits. J. Microbiol. Methods 18:91-98.

30. Krebs, C. J., Boonstra, R., Boutin, S., and Sinclair, A. R. E. 2001. What drives the 10-year cycle of snowshoe hares? Bioscience 51:25-35.

31. Larsen, M., Faedo, M., Waller, P. J., and Hennessy, D. R. 1998. The potential of nematophagous fungi to control the free-living stages of nematode parasites of sheep: Studies with Duddingtonia flagrans. Vet. Parasitol. 76:121-128.

32. Larsen, M., Wolstrup, J., Henriksen, S. A., Dackman, C., Grønvold, J., and Nansen, P. 1991. In vitro stress selection of nematophagous fungi for biocontrol of parasitic nematodes in ruminants. J. Helminthol. 65:193-200.

33. Li, Y., Hyde, K. D., Jeewon, R., Cai, L., Vijaykrishna, D., and Zhang, K. 2005. Phylogenetics and evolution of nematode-trapping fungi (Orbiliales) estimated from nuclear and protein coding genes. Mycologia 97:10341046.

34. Linford, M. B., Yap, F., and Oliveira, J. M. 1938. Reduction of soil populations of the root-knot nematode during decomposition of organic matter.
Soil Sci. 45:127-141.

35. Nagel, S. 1985. Vermehrung des mycophagen Nematoden Aphelencoides hamatus an nematophagen Pilzen. Nematologica 31:352-353.

36. Stirling, G. R. 1991. Biological Control of Plant-Parasitic Nematodes. $\mathrm{CAB}$ International, Wallingford, UK.

37. Thorn, R. G., and Barron, G. L. 1984. Carnivorous mushrooms. Science 224:76-78.

38. Waller, P. J., Schwan, O., Ljungstrom, B. L., Rydzik, A., and Yeates, G. W. 2004. Evaluation of biological control of sheep parasites using Duddingtonia flagrans under commercial farming conditions on the island of Gotland, Sweden. Vet. Parasitol. 126:299-315.

39. Wang, K.-H., Sipes, B. S., and Schmitt, D. P. 2003. Intercropping cover crops with pineapple for the management of Rotylenchulus reniformis. J. Nematol. 35:39-47.

40. Wolstrup, J., Nansen, P., Grønvold, J., Henriksen, S. A., and Larsen, M. 1996. Toward practical biological control of parasitic nematodes in domestic animals. J. Nematol. 28:129-132.

41. Yeates, G. W., Bongers, T., de Goede, R. G. M., Freckman, D. W., and Georgieva, S. S. 1993. Feeding habits in soil nematode families and genera - an outline for soil ecologists. J. Nematol. 25:315-331. 